\title{
What is the outcome of re-recurrent vs recurrent inguinal hernia repairs? An analysis of 16,206 patients from the Herniamed Registry
}

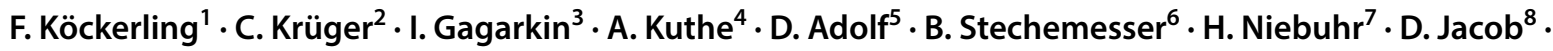 \\ H. Riediger ${ }^{9}$
}

Received: 5 November 2019 / Accepted: 6 February 2020 / Published online: 21 February 2020

(c) The Author(s) 2020

\begin{abstract}
Introduction The proportion of recurrent repairs in the total collective of inguinal hernia repairs among men is $11.3-14.3 \%$ and among women $7.0-7.4 \%$. The rate of re-recurrences is reported to be $2.9-9.2 \%$. To date, no case series has been published on second and $\geq$ third recurrences and their treatment outcomes. Only case reports are available.

Materials and methods In an analysis of data from the Herniamed Registry the perioperative and 1-year follow-up outcomes of 16,206 distinct patients who had undergone first recurrent $(n=14,172 ; 87.4 \%)$, second recurrent $(n=1,583 ; 9.8 \%)$ or $\geq$ third recurrent $(n=451 ; 2.8 \%)$ inguinal hernia repair between September 1, 2009 and July 1, 2017 were compared.

Results The intraoperative complication rate for all recurrent repairs was between 1-2\%. In the postoperative complications a continuous increase was observed (first recurrence: $3.97 \%$ vs second recurrence: $5.75 \%$ vs $\geq$ third recurrence $8.65 \%$; $p<0.001$ ). That applied equally to the complication-related reoperation rates (first recurrence: $1.50 \%$ vs second recurrence: $2.21 \%$ vs $\geq$ third recurrence $2.66 ; p=0.020$ ). Likewise, the re-recurrence rate rose significantly (first recurrence: $1.95 \%$ vs second recurrence: $2.72 \%$ vs $\geq$ third recurrence $3.77 ; p=0.005$ ). Similarly, the rate of pain requiring treatment rose highly significantly with an increasing number of recurrences (first recurrence: $5.21 \%$ vs second recurrence: $6.70 \%$ vs $\geq$ third recurrence 10.86; $p=<0.001$ ).

Conclusion The repair of re-recurrences in inguinal hernia is associated with increasingly more unfavorable outcomes. For the first recurrence the guidelines should definitely be noted. For a second and $\geq$ third recurrence diagnostic laparoscopy may help to select the best possible surgical technique.
\end{abstract}

Keywords Inguinal hernia $\cdot$ Recurrence $\cdot$ Re-recurrence $\cdot$ Outcome $\cdot$ Postoperative complications $\cdot$ Chronic pain

F. Köckerling

ferdinand.koeckerling@vivantes.de

1 Department of Surgery and Center for Minimally Invasive Surgery, Academic Teaching Hospital of Charité Medical School, Vivantes Hospital, Neue Bergstrasse 6, 13585 Berlin, Germany

2 Immanuel Hospital Rüdersdorf, Seebad 82/83, 15562 Rüdersdorf, Germany

3 Spital Riggisberg, Inselgruppe,, Eyweg 2, 3132 Riggisberg, Switzerland

4 DRK-Krankenhaus Clementinenhaus, Lützerodestr. 1, 30161 Hannover, Germany
5 StatConsult $\mathrm{GmbH}$, Halberstädter Strasse 40 a, 39112 Magdeburg, Germany

6 Pan Hospital, Hernia Center, Zeppelinstraße 1, 50667 Köln, Germany

7 Hansechirurgie, Niebuhr, Marleschki \& Partner, Alte Holstenstr. 16, 21031 Hamburg, Germany

8 COPV-Hernia Center, Kaiser-Wilhelm-Str. 24-26, 12247 Berlin, Germany

9 Vivantes Humboldt Hospital, Am Nordgraben 2, 13509 Berlin, Germany 


\section{Introduction}

According to the guidelines of the HerniaSurge Group recurrence rates of inguinal hernia repair worldwide are still too high despite numerous innovations [1]. Recurrence rates vary in accordance with the length of follow-up [1, 2]. Recurrences after inguinal hernia repairs can occur even up to 50 years later [2]. In recent administrative data and registry analyses it was revealed that the proportion of recurrent repairs in the total collective of inguinal hernia repairs among men was 11.3-14.3\% [3-7] and in women 7.0-7.4\% $[4,8]$. By contrast, in systematic reviews and meta-analyses the recurrence rates were still far lower (1.2-3\%) than those cited above since the included studies had a maximum follow-up time of 6 years [9-11].

The guidelines of the HerniaSurge Group recommend that the first recurrence repair should be performed in an unoperated anatomic layer [1], i.e. laparo-endoscopic (TEP, TAPP) following previous open anterior repair and anterior open (Lichtenstein) following previous laparo-endoscopic repair. However, to date that recommendation is not adequately applied [5] and results in significantly higher rates of second recurrences [5].

The rates of second recurrences after recurrent inguinal hernia repair are reported in registry data and case series to be as high as $8.8 \%[12,13]$. In meta-analyses comparing open with laparo-endoscopic repair of first inguinal hernia recurrences the rates of second recurrences were between $2.9 \%$ and $9.2 \%$ [14-17], depending on the follow-up time.

So far, no case series has been published on second recurrences and their treatment outcomes. Only case reports are available.

Based on the analysis of data from the Herniamed Registry, this paper now compares the treatment outcomes for second recurrences and $\geq$ third recurrences with those of first recurrences.

\section{Materials and methods}

The Herniamed quality assurance study is a multicenter, internet-based hernia registry $[18,19]$ into which 683 participating hospitals and surgeons engaged in private practice (Herniamed Study Group) in Germany, Austria and Switzerland (Status: August 1,2018) have entered data prospectively on their patients who had undergone routine hernia surgery $[20,21]$. All patients signed an informed consent agreeing to participate [20,21]. As part of the information provided to patients regarding participation in the Herniamed Quality Assurance Study and signing the informed consent declaration, all patients are informed that the treating hospital or medical practice would like to be informed about any problem occurring after the operation and that the patient has the opportunity to attend clinical examinations [20,21]. All postoperative complications occurring up to 30 days after surgery are recorded [20, 21]. At 1-year follow-up, postoperative complications are once again reviewed when the general practitioner and patient complete a questionnaire [20, 21]. At 1-year follow-up, the general practitioner and patient are also asked about any recurrences, pain at rest, pain on exertion, and chronic pain requiring treatment [20, 21]. If a recurrence or chronic pain is reported by the general practitioner or patient, the patient can be requested to attend clinical examination [20,21]. One publication has provided impressive evidence of the role of patient-reported outcome for recurrence and chronic pain [22].

In the current analysis, prospective data on patients with a first recurrent, second recurrent and $\geq$ third recurrent elective unilateral inguinal hernia were analyzed to compare the perioperative and 1-year follow-up outcomes.

The main inclusion criteria were minimum age of 16 years, unilateral first recurrent, second recurrent and $\geq$ third recurrent elective inguinal hernia repair using only the last recurrence per patient, all types of procedures, and availability of data at 1-year follow-up (Fig. 1).

All analyses were performed with the software SAS 9.4 (SAS Institute Inc., Cary, NC, USA) and intentionally calculated to a full significance level of $5 \%$, i.e. no corrections were made for multiple testing and each $p$ value $\leq 0.05$ corresponds to a significant result.

Individual outcome and influence variables (risk factors, complications) were summarized as global variables. A general, intra- or postoperative complication or risk factor was deemed to apply if at least one such individual item was present.

Therefore, all categorical patient data are presented as absolute and relative frequencies for these categories in contingency tables.

For continuous data the mean value and standard deviation or, for log-transformed data, the mean value and range are presented.

For analysis of an individual influence variable on an individual outcome parameter unadjusted analyses were carried out. Here the focus was on the influence exerted by the first recurrent, second recurrent and $\geq$ third recurrent repair.

The chi-square test was performed for categorical outcome variables. ANOVA (analysis of variance) was used for continuous variables to analyze the influence exerted by the comparison groups. 
All hernia operations with complete data entry after processing data export of August 1, 2018, at $6: 07 \mathrm{pm} \mathrm{(} \mathrm{n}=\mathbf{5 5 3 4 7 8}$ by $\mathbf{6 8 3}$ Centers)

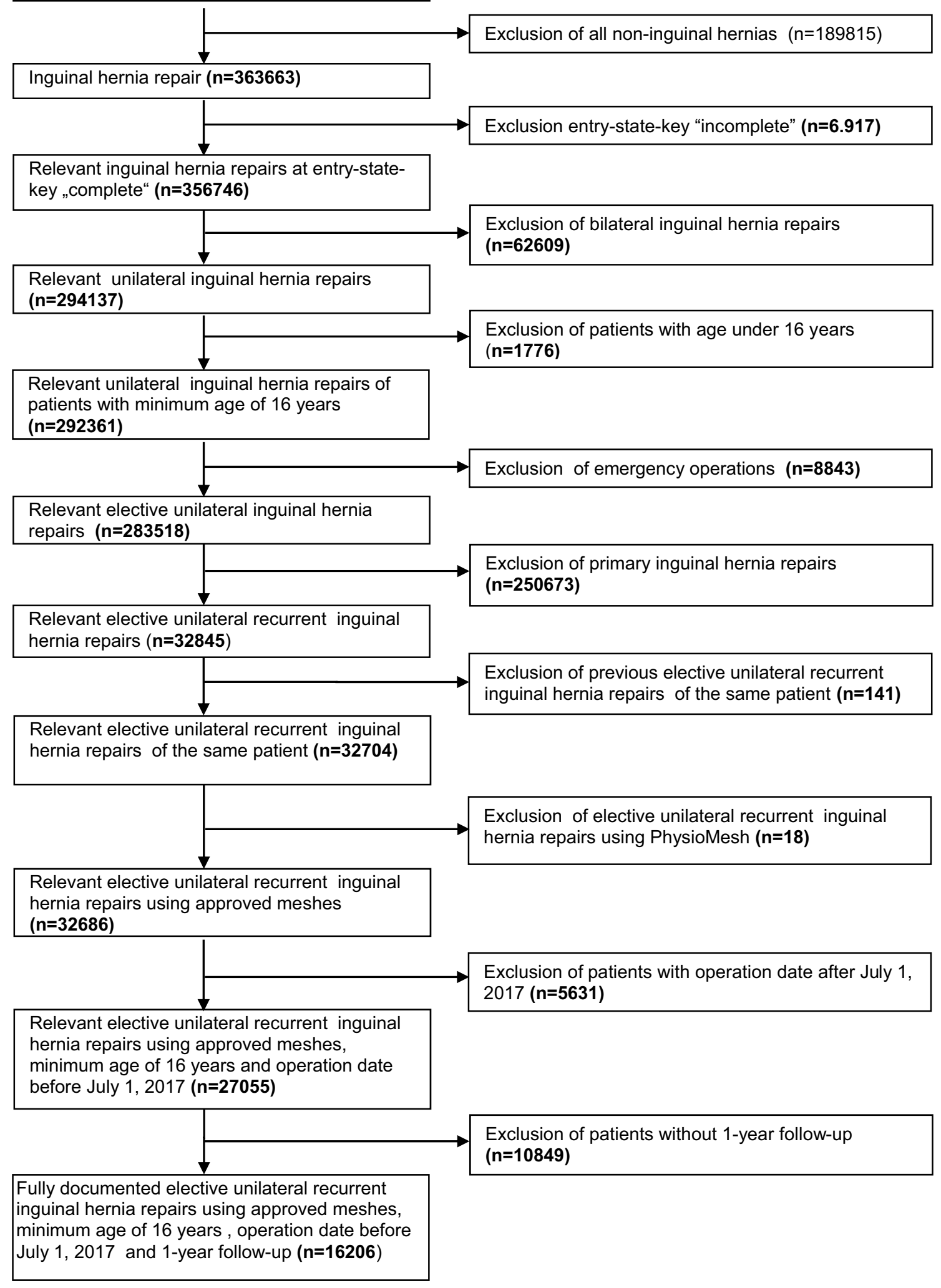

Fig. 1 Flowchart of patients inclusion 
Table 1 Patient population with 1. recurrence, 2 . recurrence and $\geq 3$. recurrence

\begin{tabular}{lll}
\hline & $N$ & $\%$ \\
\hline 1. Recurrence & 14,172 & 87.4 \\
2. Recurrence & 1583 & 9.8 \\
$\geq 3$. Recurrence & 451 & 2.8 \\
Total & 16,206 & 100.0 \\
\hline
\end{tabular}

\section{Results}

In total, 16,206 patients were selected between September 1, 2009 and July 1, 2017 (Fig. 1). Following patient selection 16,206 patients were ultimately included in the analysis comparing the outcomes for first recurrent, second recurrent and $\geq$ third recurrent inguinal hernia repair. Of these patients, $14,172(87.4 \%)$ underwent first recurrent, 1,583 (9.8\%) patients second recurrent and 451(2.8\%) patients $\geq$ third recurrent inguinal hernia repair (Table 1).

Table 2 presents the descriptive statistics as well as the test results for the continuous variables age, BMI and operating time. While there are significant differences because of the large sample size, only the difference in the operating time is clinically relevant.

Unadjusted analysis of the relationship between the first recurrent, second recurrent and $\geq$ third recurrent repair and the patient- and surgery-related variables (Table 3) revealed major differences, with the exception of the scrotal EHS classifications and most risk factors. The proportion of women rose significantly in line with the increase in the number of recurrences.

As regards the surgical techniques, the standard procedures TEP, TAPP and Lichtenstein declined somewhat in line with the rising number of recurrences, while the TIPP and other procedures increased.

Patients with a second recurrence or $\geq$ third recurrence had a significantly higher ASA score and EHS III defect size $(>3 \mathrm{~cm})$.

The proportion of medial and femoral EHS classifications rose significantly for second recurrences and $\geq$ third recurrences.

Preoperative pain was identified significantly more often for second recurrences and $\geq$ third recurrences.
The rate of risk factors (COPD, diabetes, aortic aneurysm, immunosuppression, corticoidsteroid therapy, smoking, coagulopathy, antiplateled medication and anticoagulation therapy) was significantly increased for second recurrences and $\geq$ third recurrences compared with first recurrences (Table 3).

Significant differences were identified for all outcome variables in relation to the number of instances of recurrence with the exception of intraoperative complications (Table 4).

Accordingly, the postoperative complication rate rose significantly from $3.97 \%$ for the first recurrence to $5.75 \%$ for the second recurrence and to $8.65 \%$ for the $\geq$ third recurrence $(p<0.001)$. That was also true for the complication-related reoperation rate $(1.50 \%$ vs $2.21 \%$ vs $2.66 \% ; p=0.020)$. Likewise, re-recurrence increased significantly in relation to previous recurrences at 1-year follow-up (1.95\% vs $2.72 \%$ vs $3.77 \% ; p=0.005)$. Pain at rest $(p=0.004)$, pain on exertion $(p<0.001)$ and chronic pain requiring treatment $(p<0.001)$ also rose significantly with each additional recurrence (Table 4). Chronic pain requiring treatment for the first recurrence was $5.21 \%$, for the second recurrence $6.70 \%$ and for the $\geq$ third recurrence $10.86 \%$.

Additional subgroup analysis of patients missing to follow-up.

To rule out selection bias patient subgroups with and without follow-up were compared with regard to influence factors and perioperative outcomes. The standardized differences showed a difference of $>0.1$ only for the mean age and the proportion of Gilbert repairs (Fig. 2). Since no relevant deviations were noted for any of the other influence factors or for the perioperative outcome, selection bias can be neglected.

\section{Discussion}

Analysis of 16,206 inguinal hernia recurrent repairs revealed a proportion of $87.4 \%$ for first recurrences, $9.8 \%$ for second recurrences, and $2.8 \%$ for $\geq$ third recurrences. For the intraoperative complications the number of instances of recurrence was not found to have any significant influence on the outcome. By contrast, a significantly increasing rate of postoperative complications of up to $8.65 \%$ was identified

Table 2 Comparison of mean age, BMI and operation-time in patients with 1. recurrent versus 2 . recurrent versus $\geq 3$. recurrent inguinal hernia repair

\begin{tabular}{|c|c|c|c|c|c|}
\hline & & 1. Recurrence & 2. Recurrence & $\geq 3$. Recurrence & $p$ \\
\hline Age (years) & $N /$ mean $\pm \mathrm{STD}$ & $14,172 / 61.2 \pm 15.2$ & $1583 / 62.8 \pm 14.5$ & $451 / 62.1 \pm 14.3$ & $<.001$ \\
\hline BMI $\left(\mathrm{kg} / \mathrm{m}^{2}\right)$ & $N /$ mean $\pm \mathrm{STD}$ & $14,121 / 25.9 \pm 3.5$ & $1573 / 26.0 \pm 3.6$ & $450 / 26.4 \pm 3.8$ & 0.008 \\
\hline $\begin{array}{l}\text { Log Operation-time } \\
\text { [min] }\end{array}$ & N/MW[range] & $14,029 / 52.3[50.8 ; 53.8]$ & $1573 / 57.3[55.8 ; 58.9]$ & 447 / $61.0[59.3 ; 62.6]$ & $<.001$ \\
\hline
\end{tabular}


Table 3 Comparison of demographic and surgeryrelated parameters and risk factors of patients with 1 . recurrent versus 2 . recurrent versus $\geq 3$. recurrent inguinal hernia repair

\begin{tabular}{|c|c|c|c|c|c|c|c|}
\hline & \multicolumn{2}{|c|}{ 1. Recurrence } & \multicolumn{2}{|c|}{ 2. Recurrence } & \multicolumn{2}{|c|}{$\geq 3$. Recurrence } & \multirow[t]{2}{*}{$p$} \\
\hline & $n$ & $\%$ & $n$ & $\%$ & $n$ & $\%$ & \\
\hline \multicolumn{8}{|l|}{ Gender } \\
\hline Male & 13,010 & 91.80 & 1437 & 90.78 & 399 & 88.47 & \multirow[t]{2}{*}{0.019} \\
\hline Female & 1162 & 8.20 & 146 & 9.22 & 52 & 11.53 & \\
\hline \multicolumn{8}{|l|}{ Procedure } \\
\hline Bassini & 37 & 0.26 & 11 & 0.69 & 3 & 0.67 & \multirow[t]{10}{*}{$<.001$} \\
\hline Defect closure & 4 & 0.03 & 0 & 0.00 & 1 & 0.22 & \\
\hline Gilbert & 160 & 1.13 & 21 & 1.33 & 1 & 0.22 & \\
\hline Lichtenstein & 5283 & 37.28 & 581 & 36.70 & 167 & 37.03 & \\
\hline Plug & 525 & 3.70 & 68 & 4.30 & 17 & 3.77 & \\
\hline Shouldice & 259 & 1.83 & 30 & 1.90 & 10 & 2.22 & \\
\hline Sonstige & 281 & 1.98 & 63 & 3.98 & 23 & 5.10 & \\
\hline TAPP & 5012 & 35.37 & 555 & 35.06 & 153 & 33.92 & \\
\hline TEP & 2416 & 17.05 & 222 & 14.02 & 60 & 13.30 & \\
\hline TIPP & 195 & 1.38 & 32 & 2.02 & 16 & 3.55 & \\
\hline \multicolumn{8}{|l|}{ ASA score } \\
\hline I & 3723 & 26.27 & 343 & 21.67 & 92 & 20.40 & \multirow[t]{3}{*}{$<.001$} \\
\hline II & 7893 & 55.69 & 934 & 59.00 & 263 & 58.31 & \\
\hline III/IV & 2556 & 18.04 & 306 & 19.33 & 96 & 21.29 & \\
\hline \multicolumn{8}{|l|}{ Defect size } \\
\hline $\mathrm{I}(<1.5 \mathrm{~cm})$ & 2897 & 20.44 & 316 & 19.96 & 99 & 21.95 & \multirow[t]{3}{*}{0.020} \\
\hline II $(1.5-3 \mathrm{~cm})$ & 8136 & 57.41 & 868 & 54.83 & 237 & 52.55 & \\
\hline III $(>3 \mathrm{~cm})$ & 3139 & 22.15 & 399 & 25.21 & 115 & 25.50 & \\
\hline \multicolumn{8}{|c|}{ EHS-classification medial } \\
\hline Yes & 7312 & 51.59 & 899 & 56.79 & 254 & 56.32 & \multirow[t]{2}{*}{$<.001$} \\
\hline No & 6860 & 48.41 & 684 & 43.21 & 197 & 43.68 & \\
\hline \multicolumn{8}{|c|}{ EHS-classification lateral } \\
\hline Yes & 8208 & 57.92 & 796 & 50.28 & 226 & 50.11 & \multirow[t]{2}{*}{$<.001$} \\
\hline No & 5964 & 42.08 & 787 & 49.72 & 225 & 49.89 & \\
\hline \multicolumn{8}{|c|}{ EHS-classification femoral } \\
\hline Yes & 504 & 3.56 & 98 & 6.19 & 28 & 6.21 & \multirow[t]{2}{*}{$<.001$} \\
\hline No & 13,668 & 96.44 & 1485 & 93.81 & 423 & 93.79 & \\
\hline \multicolumn{8}{|c|}{ EHS-classification scrotal } \\
\hline Yes & 280 & 1.98 & 26 & 1.64 & 13 & 2.88 & \multirow[t]{2}{*}{0.243} \\
\hline No & 13,892 & 98.02 & 1557 & 98.36 & 438 & 97.12 & \\
\hline \multicolumn{8}{|l|}{ Preoperative pain } \\
\hline Yes & 9160 & 64.63 & 1093 & 69.05 & 325 & 72.06 & $<.001$ \\
\hline No & 3797 & 26.79 & 371 & 23.44 & 78 & 17.29 & \\
\hline Unknown & 1215 & 8.57 & 119 & 7.52 & 48 & 10.64 & \\
\hline Drainage & & & & & & & \\
\hline Yes & 4305 & 30.38 & 588 & 37.14 & 198 & 43.90 & $<.001$ \\
\hline No & 9867 & 69.62 & 995 & 62.86 & 253 & 56.10 & \\
\hline Risk factors & & & & & & & \\
\hline Yes & 4440 & 31.33 & 547 & 34.55 & 164 & 36.36 & 0.003 \\
\hline No & 9732 & 68.67 & 1036 & 65.45 & 287 & 63.64 & \\
\hline COPD & & & & & & & \\
\hline Yes & 864 & 6.10 & 132 & 8.34 & 31 & 6.87 & 0.002 \\
\hline No & 13,308 & 93.90 & 1451 & 91.66 & 420 & 93.13 & \\
\hline
\end{tabular}


Table 3 (continued)

Table 4 Comparison of perioperative and 1-year follow-up outcomes in patients with 1 . recurrent versus 2 . recurrent versus $\geq 3$. recurrent inguinal hernia repair

\begin{tabular}{|c|c|c|c|c|c|c|c|}
\hline & \multicolumn{2}{|c|}{ 1. Recurrence } & \multicolumn{2}{|c|}{ 2. Recurrence } & \multicolumn{2}{|c|}{$\geq 3$. Recurrence } & \multirow[t]{2}{*}{$p$} \\
\hline & $n$ & $\%$ & $n$ & $\%$ & $n$ & $\%$ & \\
\hline \multicolumn{8}{|c|}{ Diabetes } \\
\hline Yes & 848 & 5.98 & 100 & 6.32 & 30 & 6.65 & 0.744 \\
\hline No & 13,324 & 94.02 & 1483 & 93.68 & 421 & 93.35 & \\
\hline \multicolumn{8}{|c|}{ Aortic aneurysm } \\
\hline Yes & 100 & 0.71 & 7 & 0.44 & 4 & 0.89 & 0.421 \\
\hline No & 14,072 & 99.29 & 1576 & 99.56 & 447 & 99.11 & \\
\hline \multicolumn{8}{|c|}{ Immunosuppression } \\
\hline Yes & 132 & 0.93 & 9 & 0.57 & 3 & 0.67 & 0.302 \\
\hline No & 14,040 & 99.07 & 1574 & 99.43 & 448 & 99.33 & \\
\hline \multicolumn{8}{|c|}{ Corticoid treatment } \\
\hline Yes & 164 & 1.16 & 22 & 1.39 & 3 & 0.67 & 0.432 \\
\hline No & 14,008 & 98.84 & 1561 & 98.61 & 448 & 99.33 & \\
\hline \multicolumn{8}{|c|}{ Smoking } \\
\hline Yes & 1552 & 10.95 & 203 & 12.82 & 60 & 13.30 & 0.029 \\
\hline No & 12,620 & 89.05 & 1380 & 87.18 & 391 & 86.70 & \\
\hline \multicolumn{8}{|c|}{ Coagulopathy } \\
\hline Yes & 270 & 1.91 & 24 & 1.52 & 12 & 2.66 & 0.265 \\
\hline No & 13,902 & 98.09 & 1559 & 98.48 & 439 & 97.34 & \\
\hline \multicolumn{8}{|c|}{ ASS/Plavix Antiplatelet medication } \\
\hline Yes & 1448 & 10.22 & 155 & 9.79 & 51 & 11.31 & 0.639 \\
\hline No & 12,724 & 89.78 & 1428 & 90.21 & 400 & 88.69 & \\
\hline \multicolumn{8}{|c|}{ Anticoagulation therapy } \\
\hline Yes & 393 & 2.77 & 46 & 2.91 & 19 & 4.21 & 0.188 \\
\hline No & 13,779 & 97.23 & 1537 & 97.09 & 432 & 95.79 & \\
\hline
\end{tabular}

\begin{tabular}{|c|c|c|c|c|c|c|c|}
\hline & \multicolumn{2}{|c|}{ 1. Recurrence } & \multicolumn{2}{|c|}{ 2. Recurrence } & \multicolumn{2}{|c|}{$\geq 3$. Recurrence } & \multirow[b]{2}{*}{$p$} \\
\hline & $n$ & $\%$ & $n$ & $\%$ & $n$ & $\%$ & \\
\hline \multicolumn{8}{|c|}{ Intraoperative complication } \\
\hline Yes & 187 & 1.32 & 29 & 1.83 & 7 & 1.55 & 0.239 \\
\hline No & 13,985 & 98.68 & 1554 & 98.17 & 444 & 98.45 & \\
\hline \multicolumn{8}{|c|}{ Postoperative complication } \\
\hline Yes & 563 & 3.97 & 91 & 5.75 & 39 & 8.65 & $<.001$ \\
\hline No & 13,609 & 96.03 & 1492 & 94.25 & 412 & 91.35 & \\
\hline \multicolumn{8}{|c|}{ Complication-related reoperation } \\
\hline Yes & 213 & 1.50 & 35 & 2.21 & 12 & 2.66 & 0.020 \\
\hline No & 13,959 & 98.50 & 1548 & 97.79 & 439 & 97.34 & \\
\hline \multicolumn{8}{|c|}{ Recurrence on 1-year-follow-up } \\
\hline Yes & 277 & 1.95 & 43 & 2.72 & 17 & 3.77 & 0.005 \\
\hline No & 13,895 & 98.05 & 1540 & 97.28 & 434 & 96.23 & \\
\hline \multicolumn{8}{|c|}{ Pain on exertion on 1-year-follow-up } \\
\hline Yes & 2110 & 14.89 & 326 & 20.59 & 107 & 23.73 & $<.001$ \\
\hline No & 12,062 & 85.11 & 1257 & 79.41 & 344 & 76.27 & \\
\hline \multicolumn{8}{|c|}{ Pain in rest on 1-year-follow-up } \\
\hline Yes & 1170 & 8.26 & 156 & 9.85 & 53 & 11.75 & 0.004 \\
\hline No & 13,002 & 91.74 & 1427 & 90.15 & 398 & 88.25 & \\
\hline \multicolumn{8}{|c|}{ Pain requiring treatment on 1-year-follow-up } \\
\hline Yes & 738 & 5.21 & 106 & 6.70 & 49 & 10.86 & $<.001$ \\
\hline No & 13,434 & 94.79 & 1477 & 93.30 & 402 & 89.14 & \\
\hline
\end{tabular}


Fig. 2 Standardized differences of the influencing factors and the perioperative outcomes and without follow-up between patient collectives with

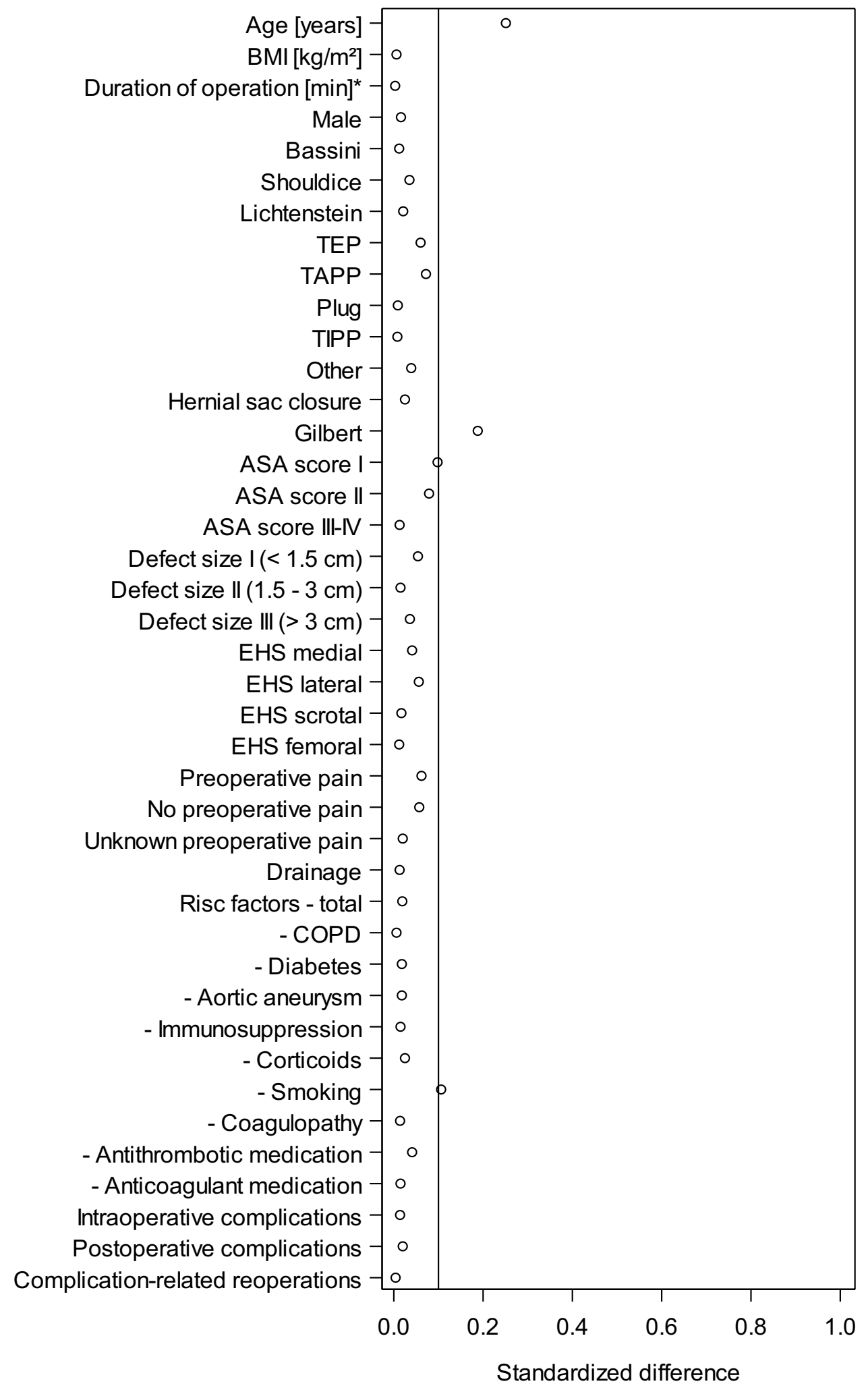

for $\geq$ third recurrences. Likewise, the complication-related instances of recurrence also had a greater influence on the pain rates. For example, for each additional recurrence the pain on exertion rate rose significantly to $23.73 \%$, the pain re-recurrence rate at 1-year follow-up also increased to $3.77 \%$ in patients with $\geq$ third recurrences. The number of 
at rest rate to $11.75 \%$ and the rate of chronic pain requiring treatment to $10.86 \%$.

Due to the relatively small number of re-recurrences, data analyses were limited to tests unadjusted for potential confounders here. Thus, estimated differences in outcome between comparison groups may further be influenced by patient- and operation-related characteristics.

Nevertheless, to date, there are no comparable findings for these data in the literature. Only the proportion of rerecurrences of around $8 \%$ is also seen in the Danish Hernia Database [11]. The data impressively demonstrate just how demanding is inguinal hernia surgery for recurrences and rerecurrences. It requires extensive experience to avoid perioperative complications, re-recurrences and chronic pain rates. Therefore, according to the HerniaSurge Guidelines [1], an expert hernia surgeon should repair a recurrent inguinal hernia after a failed anterior and posterior repair. The HerniaSurge guidelines recommend for recurrence after failed posterior repair an anterior open technique (Lichtenstein) and a laparo-endoscopic repair (TEP, TAPP) after failed anterior tissue or Lichtenstein repair [1].

For second and $\geq$ third recurrences surgeons have used the standard procedures TEP, TAPP and Lichtenstein less, opting instead for the open preperitoneal and other techniques. The same trend was observed in the registry analysis of the Danish Hernia Database [12].

Important is the finding of more medial and femoral recurrent inguinal hernias with each succeeding repair. This may reflect a reluctance to place larger meshes with more medial overlap especialy at open repair and occult or missed primary femoral hernia present at the index or recurrent operation.

Diagnostic laparoscopy can be useful for second recurrences and $\geq$ third recurrences to decide which surgical access route offers the best outcome prospects for repair of a re-recurrence $[23,24]$. The laparoscopy findings will make a valuable contribution when deciding whether a laparoendoscopic procedure or an open technique assures better conditions.

In view of the very unfavorable outcomes observed for second recurrent and $\geq$ third recurrent inguinal hernias, that additional investment is also justified. Only such supplementary diagnostic measures are able to improve the unfavorable outcomes for repair of second recurrent and $\geq$ third recurrent inguinal hernias, which should always be performed as mesh supported repair. Sometimes very individual solutions are necessary to treat a re-recurrent hernia [25].

What is true for a first inguinal hernia recurrence [1] is all the more true for a second and $\geq$ third inguinal hernia recurrence. Such a repair should only be undertaken by a highly experienced hernia surgeon while utilizing all diagnostic aids. The surgeon should have the necessary experience of all relevant surgical techniques (TEP, TAPP, Lichtenstein, open preperitoneal mesh).

Incorrect or missing data limit a registry [20]. Hospitals and surgeons participating in the Herniamed Registry sign a contract for data correctness and completeness [20]. As part of the certification process of hernia centers, experts control data entry [20].

On comparing the patient subgroups with and without 1-year follow-up to exclude selection bias, a standardized difference of $>0.1$ was found only for the mean age and the proportion of Gilbert repairs. All other potential influence factors and the perioperative outcomes were comparable.

In summary, unadjusted comparison of the perioperative and 1-year follow-up outcomes for first recurrent vs second recurrent vs $\geq$ third recurrent inguinal hernia repairs showed significantly unfavorable results. Therefore, the guidelines should definitely be followed for the first recurrent inguinal hernia repair in order to avoid further recurrences. Furthermore, inguinal hernia recurrences should only be repaired by highly experienced hernia surgeons. Diagnostic laparoscopy can help to select the best possible procedure for the individual patient.

\section{Compliance with ethical standards}

Conflict of interest Ferdinand Köckerling - Grants to fund the Herniamed Registry from Johson \& Johnson, Norderstedt, Karl Storz, Tuttlingen, pfm medical, Cologne, Dahlhausen, Cologne, B. Braun, Tuttlingen, Menke Med, Munich, Bard, Karlsruhe. C. Krüger, I. Gagarkin, A. Kuthe, D. Adolf, B. Stechemesser, H. Niebuhr, D. Jacob, H. Riediger have no conflicts of interest to disclose.

Ethical approval As only cases of routine hernia surgery are documented in the Herniamed Registry, an ethical approval was not neccessary.

Human and animal rights This article does not contain any study with animals performed by any of the authors.

Informed consent All patients with routine hernia surgery documented in the Herniamed Registry have signed an informed consent declaration agreeing to participate.

Open Access This article is licensed under a Creative Commons Attribution 4.0 International License, which permits use, sharing, adaptation, distribution and reproduction in any medium or format, as long as you give appropriate credit to the original author(s) and the source, provide a link to the Creative Commons licence, and indicate if changes were made. The images or other third party material in this article are included in the article's Creative Commons licence, unless indicated otherwise in a credit line to the material. If material is not included in the article's Creative Commons licence and your intended use is not permitted by statutory regulation or exceeds the permitted use, you will need to obtain permission directly from the copyright holder. To view a copy of this licence, visit http://creativecommons.org/licenses/by/4.0/. 


\section{References}

1. HerniaSurge Group (2018) International guideline for groin hernia management. Hernia 22:1-165. https://doi.org/10.1007/s1002 9-017-1668-x

2. Köckerling F, Koch A, Lorenz R, Schug-Pass C, Stechemesser B, Reinpold W (2015) How long do we need to follow-up our hernia patients to find the real recurrence rate? Front Surg 2:24. https:// doi.org/10.3389/fsurg.2015.00024

3. Köckerling F, Koch A, Lorenz R, Reinpold W, Hukauf M, SchugPass C (2016) Open repair of primary versus recurrent male unilateral inguinal hernias: perioperative complication and 1-year follow-up. World J Surg 40:813-825. https://doi.org/10.1007/ s00268-015-3325-9

4. Murphy BL, Zhang J, Ubl DS, Habermann EB, Farley DR, Paley K (2018) Surgical trends of groin hernia repairs performed for recurrence in medicare patients. Hernia 23:677-683. https://doi. org/10.1007/s10029-018-1852-7

5. Köckerling F, Bittner R, Kuthe A, Stechemesser B, Lorenz R, Koch A et al (2017) Laparo-endoscopic versus open recurrent inguinal hernia repair: should we follow the guidelines? Surg Endosc 31:3168-3185. https://doi.org/10.1007/s0046 4-016-5342-7

6. Siddaiah-Subramanya M, Ashrafi D, Memon B, Memon MA (2018) Causes of recurrence in laparoscopic inguinal hernia repair. Hernia 22:975-986. https://doi.org/10.1007/s1002 9-018-1817-x

7. Ashrafi D, Siddaiah-Subramanya M, Memon B, Memon MA (2019) Causes of recurrence after open inguinal herniorrphy. Hernia 23:637-645. https://doi.org/10.1007/s10029-018-1868-z

8. Köckerling F, Lorenz R, Hukauf M, Grau H, Jacob D, Fortelny R, Koch A (2019) Influencing factors on the outcome in female groin hernia repair - a registry-based multivariable analysis of 15,601 patients. Ann Surg 270:1. https://doi.org/10.1097/SLA.00000 00000003271

9. Chen LS, Chen WC, Kang YN, Wu CC, Tsai LW, Liu MZ (2019) Effects of transabdominal preperitoneal and totally extraperitoneal inguinal hernia repair: an update systematic review and metaanalysis of randomized controlled trials. Surg Endosc 33:418-428. https://doi.org/10.1007/s00464-018-6314-x

10. Bullen NL, Massey LH, Antoniou SA, Smart NJ, Fortelny RH (2019) Open versus laparoscopic mesh repair of primary unilateral uncomplicated inguinal hernia: a systematic review with metaanalysis and trial sequential analysis. Hernia 23:461-472. https ://doi.org/10.1007/s10029-019-01989-7

11. Schmidt L, Öberg S, Andresen K, Rosenberg J (2018) Recurrence rates after repair of inguinal hernia in women - a systematic review. JAMA Surg 153:1135-1142. https://doi.org/10.1001/ jamasurg.2018.3102

12. Bisgaard T, Bay-Nielsen M, Kehlet H (2008) Re-recurrence after operation for recurrent inguinal hernia. A nationwide 8-year follow-up study on the role of type or repair. Ann Surg 247:707-711. https://doi.org/10.1097/SLA.0b013e31816b18e3

13. Shah NR, Mikami DJ, Cook C, Manilchuk A, Hodges C, Memark VR, Volckmann ET, Hall CR, Steinberg S, Needleman B, Hazey JW, Melvin WS, Narula VK (2011) A comparison of outcomes between open and laparoscopic surgical repair of recurrent inguinal hernias. Surg Endosc 25:2330-2337. https:// doi.org/10.1007/s00464-010-1564-2

14. Dedemadi G, Sgourakis G, Radtke A, Dounavis A, Gockel I, Fouzas I (2010) Laparoscopic versus open mesh repair for recurrent inguinal hernia: a meta-analysis of outcomes. Am J Surg 200:291297. https://doi.org/10.1016/j.amjsurg.2009.12.009

15. Karthikesalingam A, Markar SR, Holt PJE, Praseedom RK (2010) Meta-analysis of randomized controlled trials comparing laparoscopic with open mesh repair of recurrent inguinal hernia. British J Surg 97:4-11. https://doi.org/10.1002/bjs.6902

16. Li J, Ji Z, Li Y (2014) Comparison of laparoscopic versus open procedure in the treatment of recurrent inguinal hernia: a metaanalysis of the results. Am J Surg 207:602-612. https://doi. org/10.1016/j.amjsurg.2013.05.008

17. Yang J, Tong DN, Yao J, Chen W (2013) Laparoscopic or Lichtenstein repair for recurrent inguinal hernia: a meta-analysis of randomized controlled trials. ANZ J Surg 83:312-318

18. Stechemesser B, Jacob DA, Schug-Paß C, Köckerling F (2012) Herniamed: an internet-based registry for outcome research in hernia surgery. Hernia 16:269-276. https://doi.org/10.1007/s1002 9-012-0908-3

19. Kyle-Leinhase I, Köckerling F, Jorgensen LN, Montgomery A, Gillion JF et al (2018) Comparison of hernia registries: the CORE project. Hernia 22:561-575. https://doi.org/10.1007/s1002 9-017-1724-6

20. Köckerling F, Bittner R, Kofler M, Mayer F, Adolf D, Kuthe A, Weyhe D (2019) Lichtenstein versus total extraperitoneal patch plasty versus transabdominal patch plasty technique for primary unilateral inguinal hernia repair. Ann Surg 269:351-357. https:// doi.org/10.1097/SLA.0000000000002541

21. Hoffmann H, Walther D, Bittner R, Köckerling F, Adolf D, Kirchhoff $P$ (2018) Smaller inguinal hernias are independent risk factors for developing chronic postoperative inguinal pain (CPIP) - a registry-based multivariable analysis of 57,999 patients. Ann Surg. https://doi.org/10.1097/SLA.000000000003065

22. Haapanieme S, Nilsson E (2002) Recurrence and pain three years after groin hernia repair Validation of Postal Questionnaire and Selective Physical Examination as a method of follow-up. Eur J Surg 168:22-28. https://doi.org/10.1080/110241502317307535

23. Köckerling F, Schug-Pass C (2017) Diagnostic laparoscopy as decision tool for re-recurrent inguinal hernia treatment following open anterior and laparo-endoscopic posterior repair. Front Surg 4:22. https://doi.org/10.3389/fsurg.2017.00022

24. Sakamoto K, Tokuhisa A, Nishimura K, Kamei R, Kitamura Y, Ando S, Ysmamoto T (2018) Case Report Hybrid method with explorative laparoscopy and anterior open approach for re-recurrent inguinal hernia. J Surg Case Reports 11:1-3. https://doi. org/10.1093/jscr/rjy296

25. Merali N, Verma A, Davies T (2014) An innovative repair for a re-recurrence of an incarcerated inguinal hernia. Ann R Coll Surg Engl 96:e18-e19. https://doi.org/10.1308/003588414X13946 184903081

Publisher's Note Springer Nature remains neutral with regard to jurisdictional claims in published maps and institutional affiliations. 